\section{Case Reports in Nephrology and Dialysis}

Case Rep Nephrol Dial 2021;11:78-86

DOI: $10.1159 / 000512611$

Published online: March 1, 2021

(C) 2021 The Author(s)

Published by S. Karger AG, Basel www.karger.com/cnd

This article is licensed under the Creative Commons Attribution-NonCommercial 4.0 International License (CC BY-NC) (http://www.karger.com/Services/OpenAccessLicense). Usage and distribution for commercial purposes requires written permission.

\title{
Sequential Bone Scintigraphy and the Evolution of Warfarin-Mediated Calcific Uremic Arteriolopathy
}

\author{
Peter W. Santos ${ }^{a}$ James B. Wetmore ${ }^{b}$ \\ ${ }^{a}$ Arizona Kidney Disease and Hypertension Center, Phoenix, AZ, USA; ${ }^{b}$ Division of \\ Nephrology, Hennepin County Medical Center, Minneapolis, MN, USA
}

\section{Keywords}

Bone scintigraphy · Calcific uremic arteriolopathy · Calciphylaxis · End-stage renal disease .

Warfarin

\begin{abstract}
Calcific uremic arteriolopathy (CUA), also known as calciphylaxis, is a complex syndrome of deranged mineral metabolism and vascular calcification leading to tissue ischemia that primarily occurs in end-stage renal disease (ESRD) patients on maintenance hemodialysis (HD). We report a case illustrating a temporal relationship between long-term warfarin anticoagulation and development of CUA in a patient with pre-dialysis chronic kidney disease (CKD) who progressed to ESRD. Serial ${ }^{99 m} \mathrm{mc}$-methylene diphosphonate bone scintigraphy documented the evolution of metastatic CUA over a 5-month period following HD initiation. Given the temporality demonstrated here via imaging, we speculate that warfarin's influence on vitamin Kdependent matrix Gla protein function coupled with risk factors associated with ESRD led to the development of metastatic CUA.

(C) 2021 The Author(s)

Published by S. Karger AG, Basel
\end{abstract}

\begin{tabular}{ll}
\hline & Peter W. Santos \\
Karger & Arizona Kidney Disease and Hypertension Center \\
& 5750 W. Thunderbird Road, Suite F-680 \\
Glendale, AZ 85306 (USA) \\
psantos@akdhc.com
\end{tabular}




\section{Case Reports in Nephrology and Dialysis}

\section{Introduction}

Calcific uremic arteriolopathy (CUA) is a severe, debilitating, small-vessel vasculopathy that leads to serious morbidity and mortality primarily among end-stage renal disease (ESRD) patients [1]. CUA incidence is 3.5 cases per 1,000 patient-years in patients receiving maintenance hemodialysis (HD) [2].

CUA is one of several types of extraskeletal calcification in ESRD, a phenomenon that also includes intimal, medial, and valvular calcifications. It represents the most severe form of medial vascular calcification involving arterioles manifesting as non-ulcerating cutaneous plaques, and can advance to endovascular fibrosis, tissue ischemia, and infarction [3, 4]. Tissue ischemia is caused by small-vessel mural calcification with or without endovascular fibrosis, extravascular calcification (amorphous luminal calcium), and vascular thrombosis [4]. The pathogenesis of CUA is complex and incompletely understood. Several risk factors have been identified in ESRD, including female gender, secondary hyperparathyroidism (SHPT), hyperphosphatemia, elevated calcium-phosphorus $(\mathrm{Ca} \times \mathrm{P})$ product, warfarin therapy, malnutrition, inflammation, and vitamin D analog use $[4,5]$.

We report a case in which longstanding warfarin therapy was associated with metastatic CUA only after the patient developed ESRD and HD was initiated. Consecutive $99 \mathrm{~m}$ Tc-methylene diphosphonate bone scintigraphy charted the progression of metastatic pulmonary CUA and the resistance of the disease to therapeutic interventions including discontinuation of warfarin, optimization of HD, management of bone-mineral metabolic disorders, and sodium thiosulfate (STS) administration.

\section{Case Presentation}

A 66-year-old female with ESRD secondary to hypertensive nephrosclerosis presented to our hospital complaining of bilateral lower extremity pain. Her past medical history included coronary artery disease, diastolic congestive heart failure, cerebrovascular disease, and chronic atrial fibrillation on warfarin for 3 years. She had progressed to ESRD and had been started on thrice-weekly HD 5 months prior to presentation. Physical examination was notable for several tender erythematous subcutaneous nodules with necrosis on her thighs and calves bilaterally (Fig. 1).

The monthly biochemical data and dialysis clearance profiles are shown in Table 1 . Her outpatient dialysis clearance was inadequate and her bone mineral parameters were uncontrolled prior to presentation. Other pertinent laboratory findings on presentation included a C-reactive protein level of $25.90 \mathrm{mg} / \mathrm{L}$ (normal, $<10 \mathrm{mg} / \mathrm{L}$ ) and homocysteine $>50 \mu \mathrm{mol} / \mathrm{L}$ (normal, 5-15 $\mu \mathrm{mol} / \mathrm{L}$ ). Notably, she was taking calcium acetate as a phosphate binder and receiving intravenous paricalcitol, a 1,25-vitamin D analog, with each outpatient dialysis treatment.

She underwent an extensive investigation during the index admission for presumed CUA. A magnetic resonance imaging scan, without use of intravenous gadolinium, demonstrated areas of abnormal signal intensity within the thigh muscles highly suggestive of soft-tissue

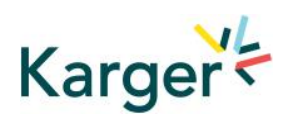




\section{Case Reports in Nephrology and Dialysis}

Case Rep Nephrol Dial 2021;11:78-86

DOI: $10.1159 / 000512611$

(C) 2021 The Author(s)
www.karger.com/cnd

Santos and Wetmore: Bone Scintigraphy and Calcific Uremic Arteriopathy

calcification. Echocardiography showed severe mitral valve calcification with restriction of both leaflets, as well as severe sclerosis of the aortic valve; both had advanced compared with echocardiography performed 6 months prior to admission. A non-iodinated contrast computerized tomography scan of the chest revealed extensive atherosclerotic calcification of the coronary arteries, mitral valve, aorta, bronchial walls, and small arteries supplying the breasts, axillae, and chest wall.

A punch skin biopsy was performed - instead of a wedge biopsy, to avoid complications such as infection, bleeding, and pain - on the periphery of the subcutaneous lesion on her left thigh corresponding to the increased signal intensity on the MRI. This yielded a mural calcification of a single deep dermal blood vessel without microvascular thrombosis, necrosis, or extravascular calcium and phosphate deposits (Fig. 2).

Serial bone scintigraphy demonstrated metastatic pulmonary CUA. Five months prior to admission, a bone scintigraphy was obtained to evaluate the cause of her rib pain (Fig. 3a); it showed no activity in the lungs or soft tissues. The bone scintigraphy at the time of CUA diagnosis, however, demonstrated extensive increased activity throughout the lungs and lower extremities (Fig. 3b).

The clinical diagnosis of CUA was made based on the physical characteristics of the lesions, risk factors, and bone scintigraphy, despite having no histological evidence of microvessel thrombosis or necrosis on the punch skin biopsy. We excluded other differential diagnoses of CUA, such as warfarin necrosis, cholesterol embolization, atherosclerosis, ischemic ulcers, and early stages of nephrogenic systemic fibrosis.

After CUA was diagnosed, lanthanum carbonate (Fosrenol ${ }^{\circledR}$ ) $500 \mathrm{mg} 2$ tablets with meals, in lieu of calcium-containing oral phosphate binders, was initiated to control her bone mineral parameters. Warfarin was discontinued, due to its ability to inactivate vitamin K-dependent carboxylation of matrix Gla protein (MGP). There were no alternative anticoagulants offered, since the patient was deemed at high risk for bleeding after the skin biopsy. HD was optimized to improve her dialysis clearance.

Despite adequate dialysis clearance and optimal control of bone mineral parameters, a repeat bone scintigraphy performed 1 month after the diagnosis showed no changes in metastatic CUA (Fig. 3c). Because of the lack of clinical improvement, we initiated treatment with STS after each HD session, beginning at a dose of $5 \mathrm{~g}$ intravenously with titration to $10 \mathrm{~g}$. The patient did not experience gastrointestinal side effects or develop metabolic acidosis from STS. Clinically, we observed slight improvement of the localized CUA on the patient's thighs, but the metastatic pulmonary CUA on the last bone scintigraphy obtained 2 months after the diagnosis remained unchanged (Fig. 3d).

Severe pain from CUA and depression marked her hospital course. Poor nutrition, as evident by her low serum albumin and phosphorus, failed to heal her CUA lesions. She requested cessation of all treatment 2 months after the diagnosis, and she expired shortly thereafter. There was no autopsy performed.

\section{Karger'=}




\section{Case Reports in Nephrology and Dialysis}

Case Rep Nephrol Dial 2021;11:78-86

DOI: $10.1159 / 000512611$

(c) 2021 The Author(s). Published by S. Karger AG, Basel www.karger.com/cnd

Santos and Wetmore: Bone Scintigraphy and Calcific Uremic Arteriopathy

\section{Discussion}

This case, the first in which serial bone scintigraphy documented the emergence of pulmonary CUA, illustrates the multifaceted and complex pathogenesis of CUA, as well as the potential utility of bone scintigraphy to detect and follow metastatic CUA. Whereas chronic kidney disease (CKD), warfarin therapy, and mitral valve calcification had been present prior to the CUA diagnosis, there was no evidence of the extensive metastatic pulmonary CUA observed on the first bone scintigraphy until localized CUA lesions became clinically apparent 5 months after HD initiation and the second bone scintigraphy captured pulmonary CUA. We believe the patient was likely predisposed to vascular calcification as a result of warfarin's $\gamma$-decarboxylation of MGP activity, resulting in loss of MGP function coupled with known risk factors associated with CUA, including female gender, SHPT, hyperphosphatemia, hypoalbuminemia, inflammation, and vitamin $\mathrm{D}$ analog administration.

The mechanistic link between warfarin and MGP vitamin K-dependent $\gamma$-carboxylation was discovered on the basis of previous animal and non-animal experimental studies in which warfarin caused MGP activity loss and depletion of vitamin $\mathrm{K}$ stores, a process that leads to severe aortic calcification and medial arterial calcification, respectively [6, 7]. These studies were complemented by clinical observational studies linking warfarin to vascular calcifications. Retrospective analysis of ESRD patients assessed for aortic valve calcification by echocardiography demonstrated a significant association between the severity of calcification and long-term use of warfarin and HD duration [8]. Furthermore, there is a more than 10-fold risk of CUA with warfarin therapy among ESRD patients on HD [9], and warfarin has been implicated as the strongest identifiable risk factor for future development of CUA in a large casecontrol study [10].

Unlike the authors of prior reports of warfarin-associated CUA, we had the opportunity to sequentially observe the emergence of metastatic pulmonary CUA and the impact of ESRD and HD on development of CUA. Serial increase in phosphorus, worsening SHPT, the use of calcium-containing phosphate binders, and initiation of vitamin $\mathrm{D}$ analogs prior to CUA diagnosis are all risk factors that could have potentiated the effects of warfarin-induced calcification $[1,11]$. Experimental models of vascular calcification demonstrated that $\mathrm{Ca}$ and $\mathrm{P}$ can induce phenotypic changes in vascular smooth muscle cells that resemble bone-promoting mineralization cells [12].

Chronic inflammation in CKD results in endothelial and vascular damage, activating key cellular and molecular elements involved in bone metabolism and repair and induction of proatherogenic cytokines [13,14]. Fetuin A, a serum glycoprotein involved in systemic clearance of excess $\mathrm{Ca} \times \mathrm{P}$ product, is often downregulated in the chronic inflammatory state that characterizes ESRD, correlating to the development of accelerated atherosclerosis and CUA in ESRD patients [15]. Regardless of the mechanisms involved, this report highlights the cumulative effects of multiple positive inducers of vascular mineralization and loss of the inhibitory function of MGP and fetuin A in the pathogenesis of CUA.

The ability of bone scintigraphy to detect CUA development is due to the uptake of a boneseeking radiopharmaceutical, a process reported in patients with metastatic calcifications in the settings of cancer, sarcoidosis, primary hyperparathyroidism, and vitamin D intoxication 


\section{Case Reports in Nephrology and Dialysis}

Case Rep Nephrol Dial 2021;11:78-86

DOI: $10.1159 / 000512611$

(c) 2021 The Author(s). Published by S. Karger AG, Basel www.karger.com/cnd

Santos and Wetmore: Bone Scintigraphy and Calcific Uremic Arteriopathy

[16-19]. An additional feature of this case is the fortuitous serial documentation of increased soft-tissue tracer accumulation by serial bone scintigraphy that correlated with the emergence of metastatic pulmonary CUA. Prior studies have reported the use of bone scintigraphy to diagnose CUA [3], and it can also detect the metastatic spectrum of CUA beyond the lesion [20]. Bone scintigraphy has a high $89 \%$ sensitivity and a $97 \%$ specificity for diagnosing CUA, and it can often be useful for early diagnosis of CUA before ulceration occurs [20] and monitoring CUA treatment response to multi-interventional modalities including STS [21].

Our serial radiographic assessment demonstrating increased soft-tissue calcification associated with the clinical emergence of CUA suggests that bone scintigraphy may provide a sensitive tool to screen and monitor selective ESRD patients with CUA at risk for metastatic calcification. This observation also points to the systemic nature of the calcification process leading to CUA, which is not merely a process of small-vessel occlusion. Furthermore, this case illustrates the refractoriness of metastatic calcification to therapies directed at reducing the factors promoting mineralization as well as discontinuation of warfarin. This contrasts sharply with the improvement of hypercalcemia-mediated soft-tissue calcifications by bone scintigraphy in patients with renal insufficiency $[16,19]$. The failure to see a short-term marked improvement of metastatic CUA in our patient despite the use of STS - a commonly used but yet unproven medical therapy, as part of a multi-therapeutic approach - suggests that long-term treatment may be required to show resolution of metastatic CUA [21].

In summary, successive bone scintigraphy scans documented the emergence of metastatic pulmonary CUA and the resistance of CUA to various treatments as the patient transitioned from late-stage pre-dialysis CKD to dialysis-dependent ESRD. Bone scintigraphy can be a complementary tool in determining the extent of CUA in certain ESRD patients. Alternative anticoagulation therapy should be considered for ESRD patients at high risk for CUA.

\section{Acknowledgement}

The authors gratefully acknowledge Nan Booth, MSW, MPH, ELS, for manuscript editing.

\section{Statement of Ethics}

The Institutional Review Board (IRB) at the University of Kansas Medical Center evaluated this case report form in accordance with its policies. The IRB's policy states that single case reports do not constitute human subjects research, and do not require IRB review or informed consent, if the report is compiled by persons already involved in the patient's care, the information is presented in deidentified form, and no changes were made in the patient's care or diagnostic testing for the sake of reportability. Further, the patient is deceased, and next of kin are not available. This case report and the use of patient information was determined to comply with the IRB policy and did not need further review (KUMC Human Research Protection Program letter: reference No. NHSR-7212019, August 18, 2020).

\section{Karger'=}




\section{Case Reports in Nephrology and Dialysis}

Case Rep Nephrol Dial 2021;11:78-86

(C) 2021 The Author(s). Published by S. Karger AG, Basel www.karger.com/cnd

Santos and Wetmore: Bone Scintigraphy and Calcific Uremic Arteriopathy

\section{Conflict of Interest Statement}

The authors declare no conflict of interest.

\section{Funding Sources}

There is no funding for this case report.

\section{Author Contributions}

The author's contributions are as follows: P.W.S. wrote the first draft and revised all versions of the manuscript; J.B.W. contributed to the draft and revised on all versions of the manuscript; both authors had the primary responsibility for the final content. Both authors read and approved the final manuscript version. Both authors meet all four ICMJE criteria for authorship, and all non-author contributors are acknowledged.

\section{References}

1 Mazhar AR, Johnson RJ, Gillen D, Stivelman JC, Ryan MJ, Davis CL, et al. Risk factors and mortality associated with calciphylaxis in end-stage renal disease. Kidney Int. 2001 Jul;60(1):324-32.

2 Nigwekar SU. Calciphylaxis. Curr Opin Nephrol Hypertens. 2017 Jul;26(4):276-81.

3 Fine A, Zacharias J. Calciphylaxis is usually non-ulcerating: risk factors, outcome and therapy. Kidney Int. 2002 Jun;61(6):2210-7.

4 Wilmer WA, Magro CM. Calciphylaxis: emerging concepts in prevention, diagnosis, and treatment. Semin Dial. 2002 May-Jun;15(3):172-86.

5 Nigwekar SU, Bloch DB, Nazarian RM, Vermeer C, Booth SL, Xu D, et al. Vitamin K-Dependent Carboxylation of Matrix Gla Protein Influences the Risk of Calciphylaxis. J Am Soc Nephrol. 2017 Jun;28(6):1717-22.

6 Luo G, Ducy P, McKee MD, Pinero GJ, Loyer E, Behringer RR, et al. Spontaneous calcification of arteries and cartilage in mice lacking matrix GLA protein. Nature. 1997 Mar;386(6620):78-81.

7 Price PA, Faus SA, Williamson MK. Warfarin causes rapid calcification of the elastic lamellae in rat arteries and heart valves. Arterioscler Thromb Vasc Biol. 1998 Sep;18(9):1400-7.

8 Holden RM, Sanfilippo AS, Hopman WM, Zimmerman D, Garland JS, Morton AR. Warfarin and aortic valve calcification in hemodialysis patients. J Nephrol. 2007 Jul-Aug;20(4):417-22.

9 Hayashi M, Takamatsu I, Kanno Y, Yoshida T, Abe T, Sato Y; Japanese Calciphylaxis Study Group. A casecontrol study of calciphylaxis in Japanese end-stage renal disease patients. Nephrol Dial Transplant. 2012 Apr;27(4):1580-4.

10 Nigwekar SU, Zhao S, Wenger J, Hymes JL, Maddux FW, Thadhani RI, et al. A Nationally Representative Study of Calcific Uremic Arteriolopathy Risk Factors. J Am Soc Nephrol. 2016 Nov;27(11):3421-9.

11 Price PA, Faus SA, Williamson MK. Warfarin-induced artery calcification is accelerated by growth and vitamin D. Arterioscler Thromb Vasc Biol. 2000 Feb;20(2):317-27.

12 Giachelli CM. Vascular calcification mechanisms. J Am Soc Nephrol. 2004 Dec;15(12):2959-64.

13 Stenvinkel P. Endothelial dysfunction and inflammation - is there a link? Nephrol Dial Transplant. 2001 Oct;16(10):1968-71.

14 Doherty TM, Asotra K, Fitzpatrick LA, Qiao JH, Wilkin DJ, Detrano RC, et al. Calcification in atherosclerosis: bone biology and chronic inflammation at the arterial crossroads. Proc Natl Acad Sci USA. 2003 Sep;100(20):11201-6. 


\section{Case Reports in Nephrology and Dialysis}

\begin{tabular}{l|l}
\hline Case Rep Nephrol Dial 2021:11:78-86 \\
\hline DOI: 10.1159/000512611 & $\begin{array}{l}\text { (c) 2021 The Author(s). Published by S. Karger AG, Basel } \\
\text { www.karger.com/cnd }\end{array}$ \\
\hline
\end{tabular}

Santos and Wetmore: Bone Scintigraphy and Calcific Uremic Arteriopathy

15 Ketteler M, Bongartz P, Westenfeld R, Wildberger JE, Mahnken AH, Böhm R, et al. Association of low fetuin-A (AHSG) concentrations in serum with cardiovascular mortality in patients on dialysis: a cross-sectional study. Lancet. 2003 Mar;361(9360):827-33.

16 Corstens F, Kerremans A, Claessens R. Resolution of massive technetium-99m methylene diphosphonate uptake in the stomach in vitamin D intoxication. J Nucl Med. 1986 Feb;27(2):219-22.

17 Reitz MD, Vasinrapee P, Mishkin FS. Myocardial, pulmonary, and gastric uptake of technetium-99m MDP in a patient with multiple myeloma and hypercalcemia. Clin Nucl Med. 1986 Oct;11(10):730.

18 Gezici A, van Duijnhoven EM, Bakker SJ, Heidendal GA, van Kroonenburgh MJ. Lung and gastric uptake in bone scintigraphy of sarcoidosis. J Nucl Med. 1996 Sep;37(9):1530-2.

19 Hwang GJ, Lee JD, Park CY, Lim SK. Reversible extraskeletal uptake of bone scanning in primary hyperparathyroidism. J Nucl Med. 1996 Mar;37(3):469-71.

20 Paul S, Rabito CA, Vedak P, Nigwekar SU, Kroshinsky D. The Role of Bone Scintigraphy in the Diagnosis of Calciphylaxis. JAMA Dermatol. 2017 Jan;153(1):101-3.

21 Araya CE, Fennell RS, Neiberger RE, Dharnidharka VR. Sodium thiosulfate treatment for calcific uremic arteriolopathy in children and young adults. Clin J Am Soc Nephrol. 2006 Nov;1(6):1161-6.

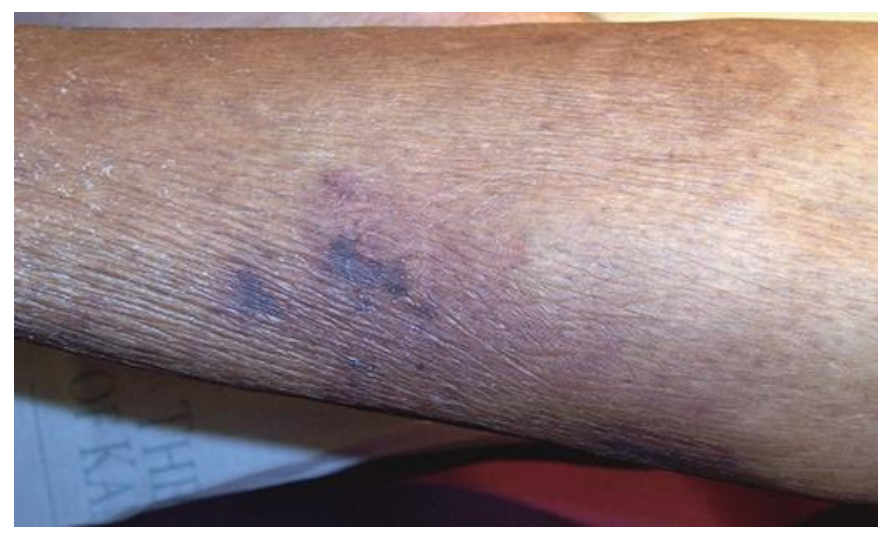

Fig. 1. Right calf showing tender erythematous nodule with necrosis. Reproduced with permission from: Nigwekar SU, Thadhani RI. Calciphylaxis (calcific uremic arteriolopathy). In: UpToDate, Post TW (Ed), UpToDate, Waltham, MA. (Accessed on June 19, 2020) Copyright(C 2019 UpToDate, Inc. For more information visit www.uptodate.com. 
Case Reports in Nephrology and Dialysis
Case Rep Nephrol Dial 2021;11:78-86

DOI: $10.1159 / 000512611$

(C) 2021 The Author(s). Published by S. Karger AG, Basel www.karger.com/cnd

Santos and Wetmore: Bone Scintigraphy and Calcific Uremic Arteriopathy

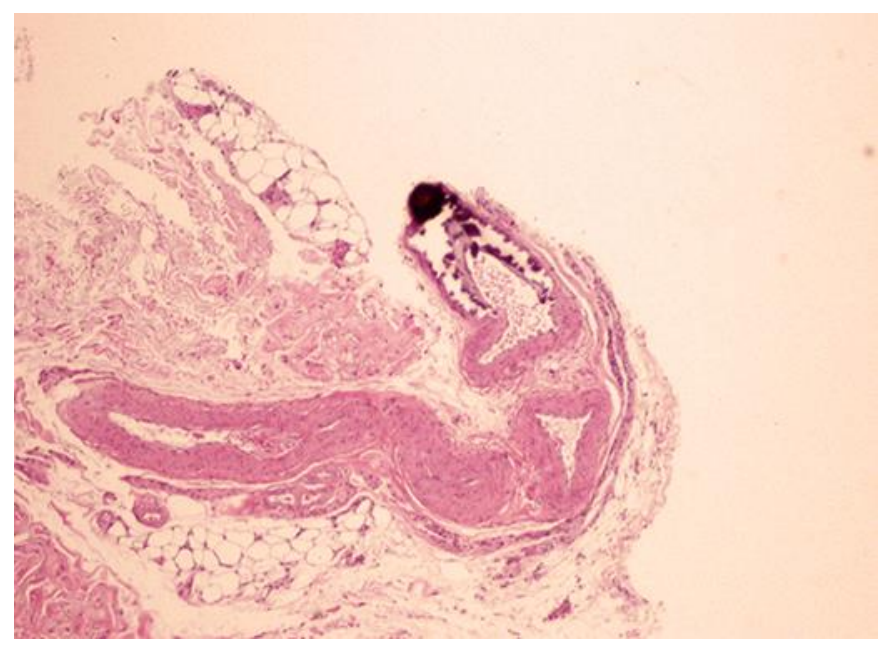

Fig. 2. Left thigh punch biopsy of a deep dermal blood vessel showing mural calcification without intimal proliferation, microvascular thrombosis, necrosis, or extravascular calcium and phosphorus deposits $(\times 200$ magnification).
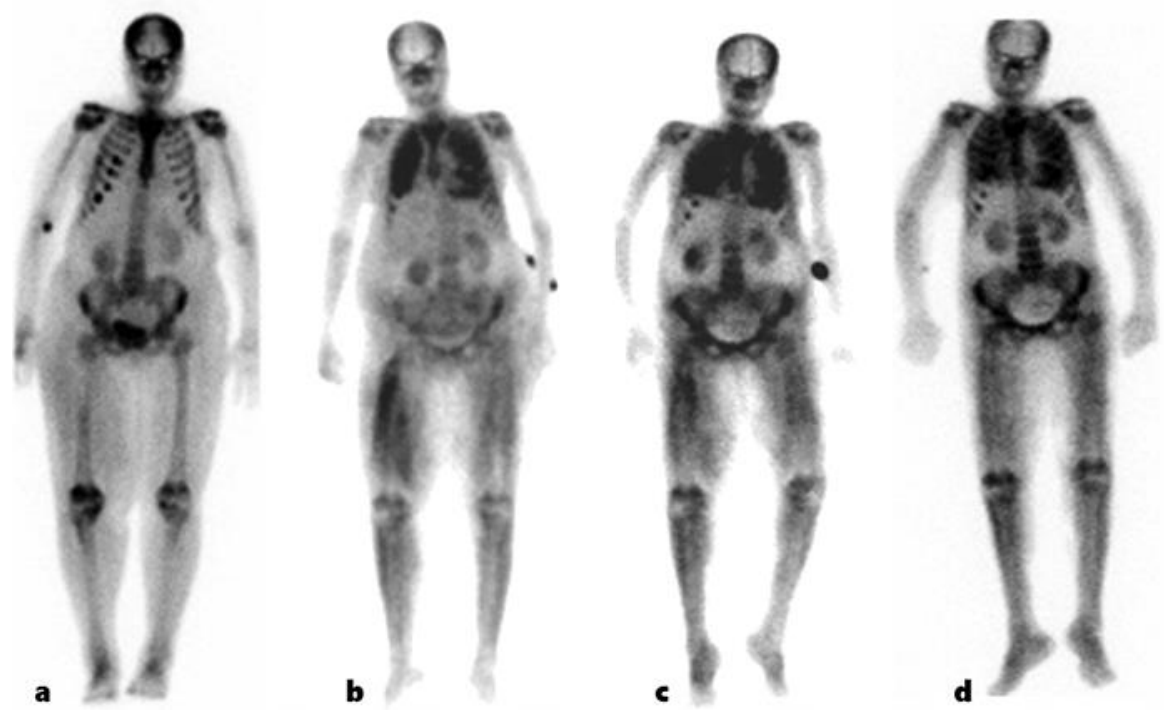

Fig. 3. ${ }^{99 m}$ Tc-methylene diphosphonate bone scan, anterior views. a No activity in the lungs and thighs 5 months prior to starting hemodialysis. $\mathbf{b}$ Extensive activity throughout the lungs and thighs, right greater than left. c Persistent activity in the lungs and thighs despite optimization of hemodialysis and control of bone mineral metabolism. $\mathbf{d}$ Persistent activity in the lungs but decreased activity in the thighs after 1 month of sodium thiosulfate. 
Case Reports in Nephrology and Dialysis
Case Rep Nephrol Dial 2021;11:78-86

(C) 2021 The Author(s). Published by S. Karger AG, Basel www.karger.com/cnd

Santos and Wetmore: Bone Scintigraphy and Calcific Uremic Arteriopathy

Table 1. Biochemical and hemodialysis clearance profile before and after the diagnosis of calcific uremic arteriolopathy

\begin{tabular}{|c|c|c|c|c|c|c|c|}
\hline Timing & $\begin{array}{l}\mathrm{Ca}(2.13-2.63 \\
\mathrm{mmol} / \mathrm{L})\end{array}$ & $\begin{array}{l}\mathrm{P}(0.81-1.45 \\
\mathrm{mmol} / \mathrm{L})\end{array}$ & $\begin{array}{l}\text { Corrected } \\
\mathrm{mmol} / \mathrm{L}^{\mathrm{a}}\end{array}$ & $\begin{array}{l}\text { Ca,PTH (10-65 } \\
\text { ng/L) }\end{array}$ & $\begin{array}{l}\text { Alb (35-55 } \\
\text { g/L) }\end{array}$ & $\begin{array}{l}\text { URR, } \\
\%\end{array}$ & $\mathrm{Kt} / \mathrm{V}$ \\
\hline \multicolumn{8}{|c|}{ Months prior to CUA diagnosis } \\
\hline $5^{b}$ & 2.02 & 1.42 & 2.30 & 479.4 & 30 & $\mathrm{n} / \mathrm{a}$ & $\mathrm{n} / \mathrm{a}$ \\
\hline 4 & 2.17 & 1.36 & 2.42 & 220.2 & 28 & 45.7 & 0.63 \\
\hline 3 & 2.30 & 1.23 & 2.48 & $\mathrm{n} / \mathrm{a}$ & 31 & 50 & 0.80 \\
\hline 2 & 2.20 & 2.03 & 2.38 & 245.3 & 31 & 43.2 & 0.53 \\
\hline 1 & 2.08 & 2.13 & 2.25 & 564.7 & 31 & 48.1 & 0.72 \\
\hline Diagnosis & 2.40 & 1.39 & 2.58 & 98.8 & 31 & 55.9 & 1.04 \\
\hline \multicolumn{8}{|c|}{ Months after CUA diagnosis } \\
\hline 1 & 1.75 & 0.65 & 2.08 & $\mathrm{n} / \mathrm{a}$ & 24 & $\mathrm{n} / \mathrm{a}$ & $\mathrm{n} / \mathrm{a}$ \\
\hline 2 & 2.13 & 0.97 & 2.58 & 49.2 & 17 & $\mathrm{n} / \mathrm{a}$ & $\mathrm{n} / \mathrm{a}$ \\
\hline
\end{tabular}

Alb, albumin; Ca, calcium; K, dialyzer clearance; $t$, dialysis time; $V$, volume of distribution of urea; $n / a$, not available; PTH, parathyroid hormone; P, phosphorus; URR, urea reduction ratio. a Albumin-corrected calcium. ${ }^{\mathrm{b}}$ Hemodialysis started. 